\title{
The Impact of Higher Education on Entrepreneurship and the Innovation Ecosystem: A Case Study in Mexico
}

\author{
May Portuguez Castro ${ }^{1}$ (D) Carlos Ross Scheede ${ }^{2}$ and Marcela Georgina Gómez Zermeño ${ }^{1, *}$ \\ 1 School of Humanities and Education, Tecnologico de Monterrey, 64849 Monterrey, Nuevo León, Mexico; \\ mayportuguezc@gmail.com \\ 2 Center for Global Innovation and Entrepreneurship, The University of Texas at Austin, 66628 Apodaca, \\ Nuevo León, Mexico; ross@cgie.org.mx \\ * Correspondence: marcela.gomez@tec.mx
}

Received: 15 August 2019; Accepted: 20 September 2019; Published: 11 October 2019

check for updates

\begin{abstract}
Entrepreneurship is recognized as an engine for the economy. However, Latin America must promote higher opportunities for the creation of new businesses, especially for technology-based ventures. In this sense, the Center for Global Innovation and Entrepreneurship (CGIE) of the University of Texas at Austin offers a Master of Science in Technology Commercialization (MCCT) that prepares students with methodologies to promote the creation of new businesses in Mexico. This study aims to know the contribution of training to the creation of new companies, and its role in the innovation and the technology transfer processes, from the viewpoint of the participants. This research presents a case study that analyzes the impact of the MCCT through the analysis of the data of a survey answered by 109 former students of this center. Findings show that the methodologies developed by the MCCT allow the creation of technology-based enterprises and entrepreneurial skills in students. This study presents good practices that can be emulated by other countries in the region, as well as recognizing the great value the role of higher education in creating synergies between actors of the innovation ecosystem that strengthen social and economic growth.
\end{abstract}

Keywords: business creation; technology transfer; innovation; innovation ecosystem; entrepreneurship education; science and technology; sustainability; higher education; educational innovation; Mexico

\section{Introduction}

In the new knowledge economy, innovation plays a fundamental role in the socio-economic development of regions [1]. This growth is associated with the dynamism of companies, especially in the roles played by small and medium businesses [2]. In this context, entrepreneurship is a factor that favors the search for opportunities and innovation with a positive impact on the countries' wealth [3]. Additionally, a sufficient mixture of specific conditions of the entrepreneur, a favorable business climate, and the needed infrastructure is required, as are legal and political conditions that encourage people to create new businesses, especially in the case of Latin America, where this performance has been weak [4].

To achieve this growth, the interaction of diverse actors of the innovation ecosystem is necessary; elements such as access to information, training of human capital through universities and research centers, access to funds, and business opportunities related to the market, customers, and suppliers affect the creation of new ventures [5]. In this interaction, institutions such as universities include educational programs for entrepreneurship to develop creative and innovative talent, which provides opportunities to generate knowledge and networks [6]. 
As mentioned earlier, human capital formation is a fundamental element of economic growth and innovation [7]. Therefore, previous studies have determined how training projects in universities help to increase the culture of innovation through the promotion of entrepreneurship. One of the studies conducted by Diamantini and Tommasone [8] in Brazil analyzes, through a case study, the contribution of the Master's degree in Innovation Management for Local Development offered by the Fluminense University of Rio de Janeiro and taught by experts from the University of Milano-Bicocca of Italy.

This Master's program provides students with tools to build new businesses and to transform their environments, especially seeking to analyze the main elements of innovation and technology transfer, which promote entrepreneurship and the relationship with other actors, such as incubators, small and medium enterprises, and technology parks. The research concluded that interaction among the different actors is needed to achieve economic growth, although it is not possible to define correct policies without knowing the ideas of those who are experiencing the situation.

Another study was made by the KICKSTART group, integrated by nine institutions of higher education from Latin America and Europe. The research objective was to seek new practices that generate innovation in the countries of the Latin American region $[9,10]$. In this study, strategies were used to improve the quality of the teaching-learning process to seek the development of professionals with an innovative approach. For instance, in research conducted in Tecnológico de Monterrey, Mexico, leadership was determined as a fundamental element that must exist in the professionals responsible for developing innovative strategies. Furthermore, this leadership should seek interaction with the tools that allow the transfer of innovative products and processes to generate projects that solve problems in their environment. However, not all teachers knew how to implement these approaches [11].

Therefore, the university needs to be involved in the innovative and entrepreneurial talent training processes, and one of its functions is to prepare citizens to join the productive processes and the generation of wealth [12]. Entrepreneurship education should support the student to learn by doing, incorporating mentors, networking, and increasing the interest of creating a new business $[13,14]$. However, authors consider that there are still programs that are closer to theory than to practice [15-18]. Thus, understanding the best practices in developing different skills in individuals to meet the new requirements becomes an indispensable factor for improving competitiveness [19].

In this context, the IC ${ }^{2}$ Institute of The University of Texas at Austin developed the Master of Science in Technology Commercialization (MSTC) in 1997 and began a similar program (MCCT) in 2009 in the city of Monterrey, Mexico, managed by the Center for Global Innovation and Entrepreneurship (CGIE). This center has graduated 250 students who have developed 54 technology-based entrepreneurship projects in Mexico. The cohorts and team membership were designed to evenly mix as managers and directors in national and multinational companies, professors and researchers in universities, and entrepreneurs. Also, a number of former students have started new ventures after taking the program.

Analyzed literature indicates that there is a gap between what universities teach and what students can apply in their lives $[20,21]$. Some programs are more theoretical than practical, which does not allow students to prepare for the needs of today's society [20]. It is also necessary to know the effects of this training on the development of the regions, but few studies have analyzed them. It is especially relevant for Latin America, where the dynamism of innovation has been limited [4,22]. Hence, this study aims to know the impact on professional development and venture creation from the viewpoint of those who received training in innovation. Also, it seeks to answer the following question: How can higher education institutions have an impact on the development of entrepreneurship and innovation? By understanding the vision of people involved, it is possible to know the contribution that this type of training has in the creation of new companies and in the processes of innovation that can generate a transformation in the social, economic, and political problems of the region.

This article is structured as follows. First, it presents the literature review related to training for innovation and technology transfer. Second, it describes the context in which it was developed. Third, research methods explain how the research was conducted. The following section presents the results 
and the analysis of the data obtained with the instrument. Finally, it develops the discussion and conclusions of the research.

\section{Literature Review}

In recent years, different studies related to the development of innovation and technology transfer have appeared, and they consider the following elements relevant for improving the economy and promoting innovation and entrepreneurship.

\subsection{Training for Innovation}

According to the Oslo Manual, innovation is a new or improved product or process, different from the original and available to users [23]. These changes promote economic and scientific progress through research and the development of new strategies [15]. Additionally, innovation is associated with the formation of human capital that has the necessary skills, because professionals who are part of the innovation processes of the public and private sectors are required to be competitive in the products and services they offer [20]. Therefore, to train future innovators, it is crucial to establish strategies that encourage creativity and promote the required skills to participate in innovation processes.

In this regard, the training processes should bring the student closer to what they will experience in real life, through a pedagogy of innovation where elements known as meta-innovations converge [21]. These elements are, according to Keinänen and Kairisto-Mertanen [20], active teaching-learning methodologies, multidisciplinary learning environments, integration of working life, research and development ( $R$ and $D)$, flexible curriculums, entrepreneurship, and internationalization. The path of the training of students to participate in innovation is in Figure 1.

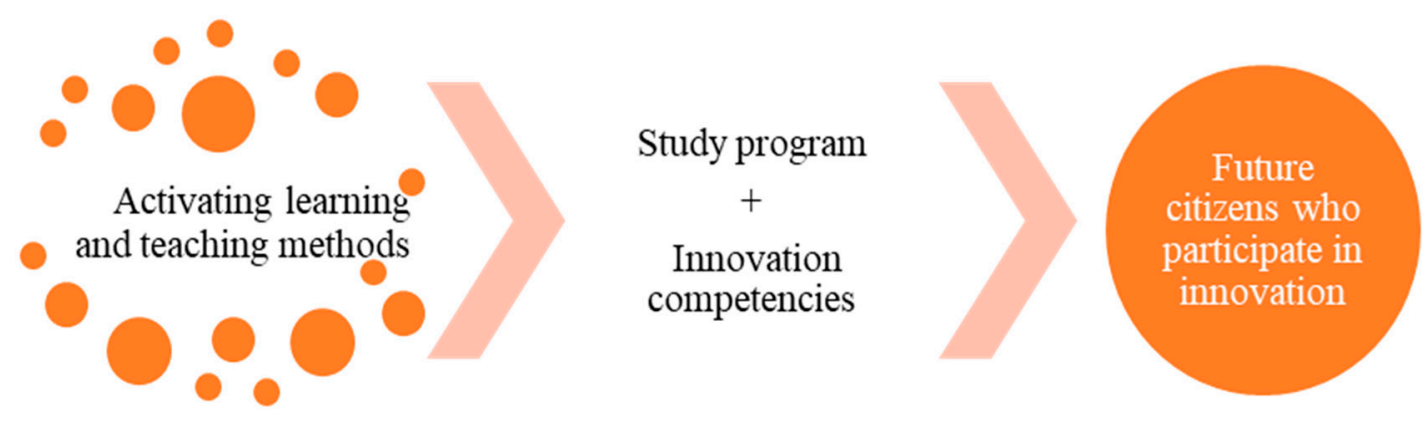

Figure 1. Path of the training of students to participate in innovation, according to Keinänen and Kairisto-Mertanen [20].

The meta-innovation processes are active learning methodologies that allow students to build knowledge and meaning to the situations they experience in the educational process, and the orientation of working life that enables learning around real-life situations working on projects with other colleagues. This participation of other people must be multidisciplinary, so that students can share competencies and interact with each other. The flexibility of the curriculum allows following different trajectories according to the needs and interests of the students. It should also give the possibility to promote entrepreneurship, which implies risk management and the search for opportunities. Finally, internationalization will make it easier to develop competencies to participate in an increasingly globalized world [24].

Entrepreneurship is a relevant factor for the economic development of a region [25]. Also, the entrepreneur's role is looking for solutions to problems and bringing these answers to the market. Schumpeter [26] states that the entrepreneur creates new ideas that lead to changing the market with new ways of doing things. This type of innovation is known as a technology push, where the entrepreneur proposes the change and can introduce a new product or a new production method, open 
a new market, or make a new industry organization. On the other hand, Kirzner [27] promotes market pull, where the needs of the market lead the entrepreneur to propose a solution [28].

For Rypestøl [25], these classifications are useful to distinguish entrepreneurs and companies, but they do not allow for determining the impact that new ventures have on the development of a region. Besides this, it is necessary to consider the effects of entrepreneur training, as well as the conditions that favor interaction with other actors such as universities, accelerators, incubators, and research centers to generate the expected development and economic growth.

\subsection{Technology Transfer}

Latin America has had an increase in entrepreneurship in recent years. However, despite its potential, this region has not achieved the dynamism of innovation that other areas have, in addition to the rise of informal enterprises [22]. As reported by Amorós et al. [4], the little development of innovative companies on this region is caused by three main reasons: 1) a lack of connection of research and development with the creation of new companies, which does not allow the transfer of technology; 2) little application of technology in business models; and 3) lack of public policies that support technology-based companies.

It is crucial to promote entrepreneurship training and innovation to reduce these causes. Furthermore, it is essential that the transfer of knowledge takes place in universities and that research and the search for solutions to society's problems make it easier to commercialize these innovations [29]. Recent studies found a gap between education for entrepreneurship and technology transfer because, in the university, commercialization of technology occurs in controlled environments and its development outside of this context is scarce [30].

An environment to form successful entrepreneurs, in which they can innovate and develop their businesses, is required. The existence of an innovation ecosystem is essential, where the conditions facilitate and give support to the entrepreneur, with an agenda that promotes the processes of entrepreneurship. The degree of success will depend on the development of a virtuous circle to improve economic development, as well as the conditions for innovation, entrepreneurship, public policies for competitiveness, and the growth of a knowledge-based economy [31].

Lackéus and Williams [32] notice that the programs that look for the creation of companies have potential to form interdisciplinary groups of students, offering a diversity of problems to solve, and a portfolio presented by the teachers. These characteristics challenge academic institutions because they require coordination among different disciplines, integration of other actors, and responsibility for the intellectual property of the ideas generated in the programs.

This study analyzes theoretical aspects, based on the opinions of the interviewees and the reality of the context in which they work. Good practices can be known to reduce the identified gap by presenting activities that are being used by higher education centers, such as CGIE, as well as showing the impact on the development of students' innovation and entrepreneurship skills, making these experiences visible in order to continue exploring their effects. The next section presents this context and contains ways in which the research gap is addressed.

\section{Context}

CGIE is in Nuevo León, Mexico, a state traditionally characterized by industrialization. In 2004, Nuevo León started a process to attract and create technology-based companies. These programs were developed by the local state government to constitute the Monterrey International City of Knowledge (MICK) in 2008, the main propositions of this model being [1]:

- Form a culture of knowledge through a long-term vision, with goals to be met by 2025 .

- Form a legal framework to guarantee the continuity of the program promoted by the Institute of Innovation and Technology Transfer (I2T2). 
- Provide the necessary resources through funds for innovation, as well as funds for seed capital to help form new companies.

The project sought to attract research centers and technology companies to achieve the vision of the model, for which the Research and Technological Innovation Park (PIIT) was created. The purposes of the PIIT were to integrate research and innovation to encourage a culture of innovation in the inhabitants, and increase the attraction of capital and the formation of high-tech industries [33]. CGIE is in this park as part of the effort to create ties among academia, industry, and government. The objective of the center is to develop educational programs that promote the commercialization of science and technology, taking advantage of the experience of the $\mathrm{IC}^{2}$ Institute to improve the economic development of the region [34].

Currently, the long-term model proposed by the Government of Nuevo León continues, with the extension of the Strategic Program in Science, Technology, and Innovation [35]. This program defines policies and actions to ensure that science and technology contribute to economic and social development. According to this report, despite current efforts, science and technology must be further developed in the state. This program is aligned with the National Development Plan, which seeks to achieve the national goals of quality education and prosperous Mexico, along with the Sustainable Development Goals concerning people and prosperity [35].

For this program, the State of Nuevo León has launched the Nuevo León 4.0 initiative, which seeks to position the city of Monterrey as "Monterrey, International City of Advanced Manufacturing and the Knowledge Economy." Therefore, the objectives defined by the PECTI 2016-2021 to promote scientific, technological, and innovation development are related to the work of CGIE. These goals are to strengthen the capacity to create and attract technology-based companies, develop leadership training programs in entrepreneurship based on innovation, promote scaling and marketing programs for new products and services, develop a network of experts to advise innovators, support the training of talent, and create international collaboration networks, among others.

The following is a description of the CGIE program and the elements that favor the achievement of the mentioned objectives. Subsequently, the answers stated by the former students are analyzed through the impact of the master's degree on supporting the development of science, technology, sustainability, and innovation as generators to achieve economic and social growth.

\section{Master of Science in Technology Commercialization (MCCT)}

CGIE imparts the MCCT in the city of Apodaca, Nuevo León, Mexico. It aims to develop skills in students that allow them to transform a technology-based product or service into a business [36]. With this program, the participant, whether an entrepreneur, researcher, academic, or technology manager, is expected to understand the process of technology transfer and value creation and develop a new business.

This master's degree program promotes students to accomplish, from the first day of classes, a real project of technology transfer following the concept of Think and Do. Students select a project from a technology portfolio and evaluate its marketing potential through the methodologies of the master's degree. The student team then develops a business model and commercialization roadmap to propose a viable business [36].

The program runs for a year and comprises 12 subjects, of which two are taught every two months, with a duration of 32 hours each, and a final project under the model of a Capstone Project. Also, an initial session is used to make the groups that develop the projects. During the program, students must generate a technology commercialization project with a practical approach. The subjects that form the study program are [37]:

- Converting technology to wealth: using the Quicklook methodology to evaluate the potential of the technology to be commercialized and defining a contextual framework to bring the technology to a market. 
- Marketing technological innovations: designing a marketing plan for the launch of a product or service based on technology using the principles of persuasion.

- Legal aspects of the marketing process: addressing aspects related to intellectual property in the development and commercialization of technology-based companies.

- Risks analysis: applying techniques to identify risks and make decisions.

- Financing new ventures: reviewing the construction and interpretation of financial statements, investment, and capital funds and the preparation of financial projections.

- Managing product development and production: the course seeks to understand customers' needs to generate a prototype.

- Technology management and transfer: understanding the models of technology transfer in national and global environments to implement them in technology adoption processes.

- Strategic analysis of technology commercialization: evaluating the potential of the industry to apply the value proposition and assessing the company's capabilities to develop a successful strategy.

- The art and science of entrepreneurship driven by the market: consisting of entrepreneurship planning and market evaluation to establish a viable business concept.

- Internationalization of technology: understanding the global processes of technology transfer to perform business processes and strategic partnerships.

- Creative and innovative management: communicating of ideas for commercialization, developing leadership skills and generating creative and innovative ideas.

- Technology enterprise design and implementation: including the necessary elements to launch a new company and identify the success factors and the risks associated with the creation of a technology startup.

CGIE participates in initiatives such as Cleantech Challenge Mexico, which is an economic development program to promote the generation and implementation of clean technology in Mexico, which trains researchers to explore the market potential of the technologies they develop [38]. And NoBI (Bi-National Innovation Nodes), with initiatives as sustainable building materials, biodegradable products, solar cells, and products for the detection of diseases such as diabetes, among others [39].CGIE's function is to support the organizers to achieve the integration of programs to support entrepreneurship for the generation, commercialization, and financing of technological solutions to environmental problems [38].

Besides this, the projects prepared by CGIE former students have been recognized as factors of change for Mexico, promoting social and economic development. For instance, some projects are for:

- Developing future entrepreneurs: Yeii (Young Entrepreneurship and Innovation International) is a business created by two alumni that seeks to form innovation and entrepreneurship among primary, middle, and high school students. The initiatives proposed by the young students attempt to solve social problems, develop their entrepreneurship and innovation skills, and participate in an authentic process of entrepreneurship [40].

- Developing a regional innovation ecosystem: Tomato Valley is an initiative carried out by two former students in western Mexico. The objective of this project is to promote technology transfer in the region's businesses which has favored the agroindustry sector that characterizes the area and the promotion of social entrepreneurship [41].

- Influencing public policy: the participation of directors and researchers of centers of the National Council for Science and Technology (CONACYT) allowed changes in public policy to adopt the practices proposed by the MCCT [42].

Currently, the concept of sustainability has expanded, and educational institutions have an interest in developing sustainable behaviors [43]. In this sense, the projects developed by alumni have allowed users to propose solutions to social problems while favoring the innovation promoted by these initiatives at the same time. 


\section{Research Methods}

The present research follows a qualitative case study methodology [44] that seeks to describe the impact of the MCCT taught by the CGIE in Mexico on the development of entrepreneurship, innovation, and technology transfer by the former students of the program. The case was selected to highlight the importance of this type of training for the development of competencies that promote competitiveness and innovation, especially in Latin American countries [8]. This methodology was selected because a case study allows enquiring into a particular case with the intent to understand a specific issue [45]. Also, the problem is best understood through an in-depth analysis of the data collected by the instrument to generate categories and subcategories of analysis based on the case study [46].

\subsection{Participants}

The study population is the 250 former students of the MCCT of CGIE. The sample consists of 109 people who completed a survey and were consulted about the impact of the MCCT for training in the commercialization and development of new technology-based companies.

\subsection{Instrument}

A survey prepared and conducted by Dr. David Gibson of the $\mathrm{IC}^{2}$ of The University of Texas at Austin from April to June 2018 collected the information. The survey is used due to the number of former students, and their geographical location in different parts of the country, this survey allowed receiving a significant amount of responses. On the other hand, according to the research design, which follows a case method that defines categories and subcategories of analysis, the data collected through open-ended questions gave extensive information about people's thought.

The instrument consists of 35 questions (Appendix A), of which the first ten correspond to the alumni's personal information, such as name, graduation year of the Master's degree, gender, age, address, other studies, and current work. There are six Likert-type questions in which the participants are asked to provide, on a scale of 1 to 5 ( $1=$ Nothing, $2=$ Very little, $3=$ Somewhat, $4=$ Much, $5=$ Very Much), their opinion on aspects related to the contribution of the Master's degree to their professional career, the relation of their current position with entrepreneurship, help from mentoring, and relationships generated in the Master's degree with their professional opportunities.

Additionally, 15 open-ended questions were included to deepen information about the experiences and learning of the alumni once they had completed the Master's degree program. For example, how has the Master's degree affected professional and business development? What was the focus of the project proposed during the Master's degree? What were the biggest challenges for the launch of that project? Have you participated in other ventures or technological transfer events related or unrelated to the Master's degree? What was the origin of the business idea? What is the size of the company? Also, what is the most significant benefit obtained? According to the qualitative research approach, the data collected from open-ended questions were taken for deeper analysis of the opinions of the participants, to answer the research question.

\subsection{Analysis of Results}

To analyze the answers of the survey, they were identified as ideas or concepts to define subcategories of analysis [45]. The review was done in the MAXQDA 12 software, to codify the answers expressed by the students and review the subcategories that emerged from the data. The categories and subcategories of analysis are in Table 1. 
Table 1. Categories and subcategories of analysis.

\begin{tabular}{|c|c|}
\hline Categories & Subcategories \\
\hline $\begin{array}{l}\text { Types of projects, including the types of projects } \\
\text { developed during the Master's degree. }\end{array}$ & $\begin{array}{l}\text { Projects: } \\
\text { Product innovation } \\
\text { Process innovation } \\
\text { Challenges: }\end{array}$ \\
\hline $\begin{array}{l}\text { Challenges faced: the main problems encountered for the } \\
\text { launch of business ideas. }\end{array}$ & $\begin{array}{l}\text { Definition of the target market } \\
\text { Viability of the product } \\
\text { Legal aspects } \\
\text { Economic resources }\end{array}$ \\
\hline $\begin{array}{l}\text { Impact of the Master's degree on professional and } \\
\text { business development. This category refers to how the } \\
\text { specific courses and knowledge acquired in the Master's } \\
\text { degree and the faculty helped the alumni to develop } \\
\text { professionally. }\end{array}$ & $\begin{array}{l}\text { Application in the current job } \\
\text { Improve knowledge } \\
\text { Vision change } \\
\text { Improve teaching practices } \\
\text { Create a new company } \\
\text { Origin of the business idea: }\end{array}$ \\
\hline $\begin{array}{l}\text { Origin of the business idea and initial capital, establishing } \\
\text { how participants conceived their business or technology } \\
\text { and how they obtained the seed capital for their venture. }\end{array}$ & $\begin{array}{l}\text { Market and customer needs } \\
\text { Share experiences with others } \\
\text { Personal and professional experience } \\
\text { Initial capital } \\
\text { Benefits: }\end{array}$ \\
\hline $\begin{array}{l}\text { Benefits of the MCCT program, indicating the most } \\
\text { significant benefit perceived by the students when taking } \\
\text { the Master's degree. }\end{array}$ & $\begin{array}{l}\text { Knowledge about technology transfer } \\
\text { Networking } \\
\text { Application to practical cases } \\
\text { Impact of the teaching staff }\end{array}$ \\
\hline
\end{tabular}

\section{Results}

This section presents the results of the survey answered by 109 former students of the MCCT, the description of the sociodemographic data of the participants, and the match between the identified categories and subcategories of analysis.

\subsection{Sociodemographic Data of the Participants}

The group of people who answered the survey consisted of 72 men and 37 women. The average age was 42 years old, and $63 \%$ of the respondents said they had completed other postgraduate courses besides the MCCT. As for their positions before entering the MCCT program, 20\% were researchers, $35 \%$ were professors and employees from universities, 20\% were managers and directors in national and multinational enterprises, and $25 \%$ were entrepreneurs. Of the interviewees, $7 \%$ said they had become entrepreneurs after the Master's degree. At the time of conducting the study, 58\% had changed their activity, 7\% indicating that they were entrepreneurs and that they were not entrepreneurs before the master's program. Thirty-seven percent lived in Nuevo León and the rest in different states of Mexico. Finally, 60\% of participants said they had participated in technology transfer events before or during the launch of a company.

\subsection{Categories}

This section presents each category found in the opinions of the former students from the Master's program.

\subsubsection{Types of Projects}

During the Master's program, students develop a commercialization project, bringing what is taught into practice by the students accompanied by the guidance of the teachers. To maintain confidentiality in the survey, answers regarding the developed ideas in the program are described in general terms. In this case, the types of projects developed were mostly oriented towards 
technology-based companies with new ideas and technology transfer, or companies already developed and implementing new methodologies.

Product innovation: some of the projects were the development of clean technologies, such as solar panels, the creation of biodegradable products, and environmental protection. Others included technologies for the food sector, agricultural, social, health, energy, electronics, biotechnology, nanotechnology, education, different types of software, and consulting.

Process innovation: In addition to innovation in products, there was also innovation in the process of methodologies, manufacturing, licensing, and marketing of new or existed products. Some of the students reported having satisfactory results: "the business focus of our project was to grow a company with a new branch within the business, which until now has been excellent since the owner of this technology continues to grow in the number of clients" (I30). However, some of the students could not apply the idea because of a lack of support from the company where it was going to be implemented, or because other colleagues did not continue with the initiative: "carry out an internal project to develop new technology. The project was proposed to the company, but there was no financial support for its execution (the company was where a teammate worked)" (I64).

Through the MCCT, I did not have the opportunity to focus on my business proposal. However, I had the opportunity to glimpse the route of the process that I had to implement the business opportunity in various technologies developed as a researcher. (I35)

\subsubsection{Challenges Faced}

Definition of the target market: Among the difficulties in developing their ideas into practice, interviewees considered market definition and determining the price of the product or service to be challenges: "The limited market and the difficulty of identifying a niche with business potential, in addition to an expensive product" (I7); "the challenges were to find the size of the market, since the software was already in use" (I93).

Viability of the product: Students found problems in evaluating the feasibility of the products, little possibility of commercialization, lack of information about the technology, outdated information, and not identifying that there were other more advanced technologies.

Legal aspects: Other difficulties, such as defining strategies and lack of distribution channels, as well as legal aspects, especially in the field of medicine, information, intellectual property, registrations, and patents were mentioned as follows: "create a business model acceptable to the market and with adequate profitability, as well as diversify technology applications. Another complicated task was decision-making regarding negotiating the licenses" (I29). "That companies are afraid to try new things, are not very identified with innovation and technology, and many companies do not see the need to go hand in hand with these concepts" (I27).

To understand the technology and the degree of development of the same, to be able to decide if it was or not ready to be commercialized, besides the valuation of the same one. On the other hand, the treatment related to intellectual property, due to the zeal of the researcher who was not willing to discuss the possibilities with the team. (I53)

Economic resources: Economic aspects were also mentioned, such as having few resources or difficulty finding seed capital.

\subsubsection{Impact of the Master's Degree on Professional and Business Development}

Application in the current job: the impact on professional development was noticed, as: "much of the acquired knowledge has helped me perform better in my new position in the organization, understanding situations in a better way" (I53), "I collaborate with a work team at a national level, working on the science and technology commercialization model, as well as the regulation for linking and innovation activities I am a recurrent guest at workshops and competitions for innovation and 
entrepreneurship" (I54); "thanks to the fact that I studied the MCCT, I could be in charge of different areas related to entrepreneurship in my work, and from there my professional growth began" (I66). As can be noted from the responses provided, students could apply the knowledge learned in the courses to their daily lives.

Improve knowledge: the interviewees said they obtained learning, such as knowledge about technological development and innovation, the commercialization of created products, intellectual property, patents, and utility models. As they mentioned: "I learned how to complement the process of research and generation of knowledge with the commercialization of the products generated" (I83), "it has helped me a lot concerning my professional development, teamwork, strategy, product, models, technology, patents, legal, and relationships. I feel that it is the side that I needed to develop" (I3).

Vision change: participants expressed that in the Master's degree, they were given a new perspective to look for solutions to the problems, as well as to use the knowledge to generate valuable products for the market: "this Master's degree opens your vision about the needs of the environment and helps you to understand that everything can be achieved by carrying out a good implementation plan. I apply it a lot, looking for new things and new solutions to what is presented day by day" (I30), "with the vision developed after acquiring the knowledge, I have a different perspective on addressing different problems and visualizing solutions" (I26). This change of vision and the knowledge acquired also moved former students to improve teaching practices and to teach others to develop businesses with these methodologies.

Improve teaching practices: some participants are applying their knowledge to promote entrepreneurship with their students, using them in courses they develop to generate projects based on technology and innovation, which allows them to extend the scope of the content seen in the Master's degree to other contexts.

I continue reading books related to the topics examined in the MCCT, and I have incorporated some practices of teachers in my classes. Interest in science, technology, transfer of knowledge and technology, intellectual property, risk analysis, marketing, finance, and entrepreneurship, were not of my interest and now they are. I force myself to continue participating in projects where these issues take place. (I54)

Creation of new companies: after the Master's degree, the former students had carried out several ventures, such as software development companies, food products, technological developments, technology transfer offices, educational services, recruitment of personnel, public transport, intra-enterprise projects, family businesses, consulting, and other ongoing projects. As was mentioned by the entrepreneurs: "I am currently starting a technology-based venture and I have applied the knowledge of MCCT at all times"(I27), "the position I currently hold and my area of academic performance are highly related to the momentum in the creation of technology-based companies, technology transfer, innovation, and entrepreneurship. Currently, one of the academic programs has a specialty in Technological Innovation" (I42).

\subsubsection{Origin of the Business Idea and Initial Capital}

Market and customer needs: Typical responses were that the developed idea responded to a market need and customer demands, and this was recognized thanks to observation: "from the observation and analysis of my day-to-day work, as well as the identification of a need to be able to monitor performance efficiently in order to make quick decisions in a very demanding food product development environment" (I3), "of the ideas that arose when we were looking for the project and seeing an unmet need in the market" (I15), "we generated it by noticing the need of clients located in Nuevo León" (I21).

Share experiences with others: also, the origin of the business idea was thanks to the opinions of colleagues in the Master's degree, or other ideas that they were developing in their companies and had 
decided to continue as a study project. For example, one of the interviewees commented: "it was not my technology; we transferred technology from universities in other countries" (I7).

Professional and personal experiences: these experiences helped them to determine which products or services to offer to the market. As they commented: "the idea came when I was working as a professor at a university" (I8), "it was circumstantial when we enrolled our first-born in a school" (I5). Sharing experiences was also a reason for the conception of business ideas. Interviewees mentioned that this originated from talks, in the courses, about reviewing opportunities with other colleagues from the industry or sector. In the end, the entrepreneur is the person who has the idea and develops it.

Initial capital: In this category, the primary sources of business ideas were responding to market needs, to the requirements of clients, from sharing with others and from their personal and professional experiences. Most of the resources came from their funds, the government and private initiative, or a combination of these. They also came from partners, angel investors, family, and friends.

\subsubsection{Benefits of the MCCT Program}

Knowledge about technology transfer: the interviewees stated that the main benefit obtained from the program was having learned how to bring ideas to the market through knowledge of the methodologies learned in the Master's degree: "learn how to create a strategy, how a business works, how the teams interact in order to create a successful launch, and develop my inspirational, persuasive leadership skills and bring others with me" (I15).

Networking: another valuable element was networking, which allowed them to share the ideas generated with colleagues and professors, as well as to associate the acquired knowledge with real experiences of entrepreneurship, expanding their vision. In this sense, one of the interviewees stated: "improves the vision of the scope and potential (that we still have to do), of the real transfer processes and the path towards the foundation and growth of technology-based companies, and definitely, the colleagues and staff" (I23), "as I commented, it changed the way of seeing things and of being conformist, in the way I work and in my entrepreneurial activities" (I29).

Application to practical cases: the acquired knowledge is highly valuable for application to their environments, as mentioned by former students: "the knowledge, methodologies, and successful practices of how to do technology transfer. I am working to promote new internal policies and procedures and the culture of the rest of the company's staff" (I22); "definitely specialized knowledge in various areas associated with the creation of projects and businesses based on knowledge, but just as important is the collaboration network that was formed in our cohort" (I35).

The greatest benefit that I have obtained has been the learning, knowledge, and implementation of successful methodologies to research towards the development of innovative products that have a social and economic impact. I believe that this will only be achieved if you can work in synergy with the main actors in the whole value chain in which even the MCCT'S companions have a presence and collaborate with them effectively following appropriate guidelines of the organization, communication, and legal aspects. (I53)

As interviewees indicated, the networking and the interaction with colleagues and professors were of great value.

Impact of the teaching staff: respondents mentioned that the transmitted experiences helped to improve the way of making decisions, and they learned from teachers how to analyze market opportunities, how to develop skills for their projects, and the importance of teamwork. Participants stated the transfer of knowledge of methodologies taught in classes to their current activities. Methods such as Quicklook, use of simulators, marketing, intellectual property, interview techniques, persuasion, and decision trees have been applied after the courses.

As comments, they expressed that: "the methodologies of the teaching process of all the teachers of the MCCT is different and of very good quality; I have used the best of each one to bring to the practice to my daily professional activities"(I52), "here are many examples, but to name one of them 
was the Intellectual Property class, where the professor showed great experience and knowledge in that area that moved me to learn more about it and now is one of my favorite topics" (I59). "I have been able to apply knowledge and experiences in activities of a different nature that are part of my functions, from applying the methodology of risk analysis to soft skills such as writing a persuasive proposal" (I86).

Finally, as a reflection of the application of these methodologies and knowledge, the interviewees think that Mexico should continue towards the development of technologies, considering that in the field of technology transfer, innovation is incipient and scarce in this country:

The practices and methodologies are very successful. I thought it would be very easy to apply them in Mexico, but experience has shown me that although there is more talk about technology transfer, a generalized culture of innovation and entrepreneurship is needed, mainly between research centers and industry. (I28)

\section{Discussion}

The development of human capital is essential to enable innovative processes to impact the economy of a country. This influence is possible if education promotes the generation of ideas and ventures [15]. Several studies have criticized higher education institutions for not preparing students with the necessary innovation skills, since traditional forms of teaching such as reading, evaluating through memory, and working individually rather disfavor them $[18,19]$.

Methodologies in the MCCT allow the advancement of technology-based entrepreneurship and entrepreneurial skills in students. Thanks to the search for value propositions in the use of technologies, entrepreneurs find applications that solve problems. In this case, the student becomes a relevant actor in contributing to the solution of environmental issues and collaborates in economic development [25].

The teaching-learning processes of the MCCT contain meta-innovations and elements of active learning, thanks to the use of the Think and Do methodology, participation in interdisciplinary collaborative projects, and with the support of expert teachers [20].

The learning has an impact on the entrepreneur that is recognized by the surveyed students, especially in a change of vision where they use what they learned in the context in which they work. Also, as Lehto and Penttilä [24] state, meta-innovation processes allow participants to develop capacities to participate in an increasingly globalized world. The international collaboration of professors from The University of Texas at Austin exposes Mexican students to other experiences and prepares them for internationalization.

When analyzing the context, the objectives of the Master's degree are aligned with the State Development Plan of Nuevo León [35], especially in its work to strengthen the creation of companies based on technology, the development of programs for creating these companies, the formation of entrepreneurial talent, and internationalization. Requiring the students to create new companies also prepares them for the challenges that arise when putting ideas into practice. Students recognize the difficulty of satisfying the needs of customers and the market, little information about the use of technology, and, in some cases, the challenge in obtaining resources. Therefore, it is suggested to continue with the virtuous circle of entrepreneurship by increasing the link with other actors of the innovation ecosystem, as recommended by Maroufkhani et al. [31].

The importance of these findings is that they allow for identifying good practices in the role of higher education to create synergies among actors of the innovation ecosystem [9,10]. Also, it contributes to the discussion of the functions of a university in a transnational context, considering that the Latin American region may benefit from these initiatives of integration with universities that have developed the theme of entrepreneurship and innovation for a long time [4]. Finally, understanding dynamic factors and roles will empower actors to generate innovation and sustainable practices [38]. 


\section{Conclusions}

This study shows that the State of Nuevo León in Mexico has the necessary conditions for the development of companies based on science and technology. The long-term development plans with a clear vision, the required infrastructure for their achievement, and the participation of actors of the innovation ecosystem, are favorable conditions to achieve the goals that lead to the economic development of the state and the country. However, according to the results shown by the PECTI 2016-2021, it is still necessary to improve to reach the expected levels of development and innovation. Therefore, the role of the CGIE through the MCCT and the activities it develops can help to achieve them.

In the presented analysis, it was possible to determine that the students developed innovation and entrepreneurship skills. Also, they applied what they learned to their business ideas, in other companies and training processes for other entrepreneurs. Besides this, they were able to create a network with colleagues and teachers that allowed them to improve and implement their ideas.

Regarding the question of how higher education institutions can affect the development of entrepreneurship and innovation, the analyzed case study shows that the methodologies evolved in the MCCT allowed students to develop skills for innovation, technology transfer, the creation of new companies, the commercialization of new ideas, and entrepreneurial abilities. The application of these methodologies has favored the emergence of sustainable initiatives within the students' projects. Moreover, they have allowed the generation of companies that help other entrepreneurs to develop solutions to environmental and social problems.

As the primary concern, the former students pointed out that there is limited development in the field of technology transfer and commercialization in Mexico, a problem faced by other Latin American countries.

The role of CGIE is fundamental for improving these results through the training of human capital in innovation, and the development of ideas to solve these types of problems through new technologies. So, linking with other academic institutions and industry can increase the impact of the specialists trained at the center. For the local government, it is also an opportunity to learn more about these entrepreneurship training programs to apply them in a larger population, implementing more business ideas. For industries, they can also give ideas to the students. Learners can develop solutions they need, and businesses can collaborate with the employment of these professionals.

Other countries in Latin America can emulate good practices presented in this case study. Although some students are from the same geographical area, there are also learners from different states of the country. In this circumstance, training can improve the results of the impact and economic growth at the state, the country, and regional levels.

For future studies, it is suggested to analyze in quantitative terms the value of the companies created in the Master's degree and the contribution of these companies to the state and country Gross Domestic Product (GDP). It is also recommended to investigate success stories for knowing in more detail about the applied practices of the MCCT and the social problems solved by these companies. Another suggestion would be to examine the actions of other participants of the innovation ecosystem in Nuevo León, such as accelerators, research centers, and technology parks, and their results for economic development.

Finally, continue analyzing the role of education for entrepreneurship and innovation, and its implementation through projects applied to the solution of real problems that result in high-impact technology companies, with the dissemination of good practices such as those presented in this case study. At a conference held in the city of Dallas, Texas in 1997, George Kozmetsky, founder of the IC ${ }^{2}$ Institute, gave his vision of the impact of technology in the 21st century and of the transformation towards a knowledge society:

Business leadership has the ability to manage the value-added chain, the technology chain, and knowledge innovation chains, simultaneously. The knowledge innovation chain is "the creation, evolution, exchange, and application of new ideas into marketable goods and services for the excellence 
of an enterprise, the vitality of a nation's economy, and the advancement of society as a whole. It is the velocity of change. In short, the knowledge society breaks the old 1990s MBA. Enterprise creation and innovation is an emerging competitive digital technology-based economy realizing the value of interdependencies rather than close-kept intellectual property assets of the last twenty-five years. [47] (p. 21)

All these elements are still valid for the formation of human capital and entrepreneurial talent, an essential component to impact the economic and social development of the region.

Author Contributions: Conceptualization, M.P.C. and C.R.S.; methodology, M.P.C. and M.G.G.Z.; validation, M.P.C., C.R.S. and M.G.G.Z.; software M.P.C.; writing—original draft preparation, M.P.C.; writing-review and editing, C.R.S. and M.G.G.Z.; supervision, C.R.S. and M.G.G.Z.

Funding: The authors would like to acknowledge the financial support of Writing Lab, TecLabs, Tecnologico de Monterrey, Mexico, in the production of this work.

Acknowledgments: We acknowledge the Center for Global Innovation and Entrepreneurship of The University of Texas at Austin for its support in our research. We also are grateful to the peer reviewers' valuable comments, which has helped us to improve the paper.

Conflicts of Interest: The authors declare no conflict of interest.

\section{Appendix A}

\section{MMCT impact survey.}

Q1. What is your full name?

Q2. What year did you graduate from MCCT?

Q3 What is your gender?

Q4. How old are you?

Q5. Besides MCCT, do you have other degrees? What are they and where was obtained?

Q6. What organization did you work for? and what was your position before entering the MCCT program?

Q7. What city do you currently live?

Q8. What organization do you currently work?

Q9. What is your current position/title?

Q10. What is your contact information (mail, phone)?

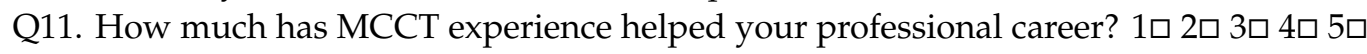

Q12. How directly your current position relates to entrepreneurship and business development? $1 \square 2 \square 3 \square 4 \square 5 \square$

Q13. How much have the specific courses and knowledge of MCCT to your professional development and business experiences? $1 \square 2 \square 3 \square 4 \square 5 \square$

Q14. Please explain your answer.

Q15. How the mentoring and connections of the professors and MCCT staff have helped you with your professional opportunities? $1 \square 2 \square 3 \square 4 \square 5 \square$

Q16. Please explain your answer.

Q17. How much have you benefited from your connections with colleagues from class in your professional and business opportunities? $1 \square 2 \square 3 \square 4 \square 5 \square$

Q18. Please explain your answer

Q19. What was the business focus of your MCCT project? Please explain your answer.

Q20. What were the biggest challenges for the launch of your company during the MCCT program? Please explain your answer.

Q21. Do you have participated in other ventures (related or not to MCCT) after graduating from the MCCT program? Please explain and Name the companies.

Q22. Have you participated in a technology transfer event or the launch of a company? Yes $\mathrm{No} \square$

Q23. How long had/has the company existed? (Years and months) 
Q24. Where did your technology business idea come?

Q25. Where did the seed capital come?

Q26. How many employees did your company have or have now?

Q27. The company still exists or was sold or licensed to another company?

Q28. Who are the main clients of the business/technology?

Q29. Do you keep in touch with other members of your project team of MCCT? Please explain your answer. Yes $\square$ Nor

Q30. How often do you communicate with your colleagues in the generation?

Q31. With how many of your colleagues from other generations of MCCT, you communicate?

Q32. Indicate all the forms of communication do you use to contact your MCCT partners?

Q33. Did have left a continuous impact on the knowledge and experience of MCCT teachers in your professional development? $1 \square 2 \square 3 \square 4 \square 5 \square$

Q34. Please give a specific example.

Q35. What has been the most significant benefit do you have obtained from the program MCCT? Please explain your answer.

\section{References}

1. Leal González, M.; Parada Ávila, J.; Gómez Zermeño, M.; Alemán de la Garza, L. A model for innovation and global competitiveness: The Monterrey International City of Knowledge Program (MICK). In Innovation Support in Latin America and Europe: Theory, Practice and Policy in Innovation and Innovation Systems; Anderson, M., Edgar, D., Grant, K., Halcro, K., Rodríguez, J., Guera Genskowsky, L., Eds.; Routledge: Glasgow, Scotland, 2014; pp. 105-128.

2. Levie, J.; Autio, E. Regulatory burden, rule of law, and entry of strategic entrepreneurs: An international panel study. J. Manag. Stud. 2011, 48, 1392-1419. [CrossRef]

3. Urbano, D.; Alvarez, C. Institutional dimensions and entrepreneurial activity: An international study. Small Bus. Econ. 2014, 42, 703-716. [CrossRef]

4. Amorós, J.; Poblete, C.; Mandakovic, V. R\&D transfer, policy and innovative ambitious entrepreneurship: Evidence from Latin American countries. J. Technol. Transf. 2019, 44, 1-20. [CrossRef]

5. Van Stel, A.; Suddle, K. The impact of new firm formation on regional development in the Netherlands. Small Bus. Econ. 2008, 30, 31-47. [CrossRef]

6. Florida, R. The creative class and economic development. Econ. Dev. Q. 2014, 28, 96-205. [CrossRef]

7. Pelinescu, E. The impact of human capital on economic growth. Procedia Econ. Financ. 2015, 22, 184-190. [CrossRef]

8. Diamantini, D.; Tommasone, M. Dissemination innovation by improving individual capabilities: A Brazilian experience. In Innovation Support in Latin America and Europe: Theory, Practice and Policy in Innovation and Innovation Systems; Anderson, M., Edgar, D., Grant, K., Halcro, K., Rodríguez, J., Guera Genskowsky, L., Eds.; Routledge: Glasgow, Scotland, 2014; pp. 171-200.

9. Anderson, M.; Edgar, D.; Grant, K.; Halcro, K.; Rodríguez, J.; Guera Genskowsky, L. Innovation Support in Latin America and Europe: Theory, Practice and Policy in Innovation and Innovation Systems; Routledge: Glasgow, Scotland, 2014.

10. Alemán de la Garza, L.; Gómez Zermeño, M. Liderazgo docente para la enseñanza de la innovación. RIEEGE 2012, 2, 2-7.

11. Alemán de la Garza, L. Liderazgo para la Innovación en las Instituciones de Educación Superior; Nómada: Monterrey, Mexico, 2018.

12. Edwards-Schachter, M.; García-Granero, A.; Sánchez-Barrioluengo, M.; Quesada-Pineda, H.; Amara, N. Disentangling competences: Interrelationships on creativity, innovation and entrepreneurship. Think. Sk. Creat. 2015, 16, 27-39. [CrossRef]

13. Kariv, D.; Cisneros, L.; Ibanescu, M. The role of entrepreneurial education and support in business growth intentions: The case of Canadian entrepreneurs. J. Small Bus. Entrep. 2019, 31, 433-460. [CrossRef]

14. Pauwels, C.; Clarysse, B.; Wright, M.; Van Hove, J. Understanding a new generation incubation model: The accelerator. Technovation 2016, 50, 13-24. [CrossRef] 
15. Alawamleh, M.; Bani, L.; Aqeel, D.; Alawamleh, K. The bilateral relationship between human capital investment and innovation in Jordan. J. Innov. Entrep. 2019, 8. [CrossRef]

16. Qiao, L. Cultivation of innovators and entrepreneurs in colleges and universities in "Internet+" Era. Educ. Sci. 2018, 18, 3449-3455. [CrossRef]

17. Quintana, C.D.D.; Mora, J.; Pérez, P.J.; Vila, L.E. Enhancing the development of competencies: The role of UBC. Eur. J. Educ. 2016, 51, 10-24. [CrossRef]

18. Virtanen, A.; Tynjälä, P. Factors explaining learning of generic skill: A study of university students' experiences. Teach. Higher Educ. 2018, 24. [CrossRef]

19. Avvisati, F.; Jacotin, G.; Vincent-Lancrin, S. Educating higher education students for innovative economies: What international data tell us. Tuning J. Higher Educ. 2013, 1, 223-240. [CrossRef]

20. Keinänen, M.; Kairisto-Mertanen, L. Researching learning environments and students' innovation competences. Educ. Train. 2019, 61, 17-30. [CrossRef]

21. Penttilä, T. Developing educational organizations with innovation pedagogy. Int. E J. Adv. Educ. 2016, 2, 259-267. [CrossRef]

22. Aparicio, S.; Urbano, D.; Audretsch, D. Institutional factors, opportunity entrepreneurship and economic growth: Panel data evidence. Technol. Forecast. Soc. Change 2016, 102, 45-61. [CrossRef]

23. OECD/Eurostat. Oslo Manual 2018: Guidelines for Collecting, Reporting and Using Data on Innovation; OECD: Paris, France, 2018.

24. Lehto, A.; Penttilä, T. Pedagogical Views on Innovation Competencies and Entrepreneurship: Innovation Pedagogy and Other Approaches; Tampereen Yliopistopaino: Turku, Finland, 2013.

25. Rypestøl, J. Regional industrial path development: The role of new entrepreneurial firms. J. Innov. Entrep. 2017, 6. [CrossRef]

26. Schumpeter, J. The Theory of Economic Development; Harvard University: Cambridge, MA, USA, 1934.

27. Kirzner, I. Competition and Entrepreneurship; University of Chicago Press: Chicago, IL, USA, 1973.

28. Arielle, J.; Storr, V. Kirznerian and Schumpeterian entrepreneurship in Trinidad and Tobago. J. Enterp. Commun. 2018, 12, 582-610. [CrossRef]

29. Weckowska, D. Learning in university technology transfer offices: Transactions-focused and relations-focused approaches to commercialization of academic research. Technovation 2015, 41-42, 62-74. [CrossRef]

30. Boh, W.F.; De-Haan, U.; Strom, R. University technology transfer through entrepreneurship: Faculty and students in spinoffs. J. Technol. Transf. 2016, 41, 661-669. [CrossRef]

31. Maroufkhani, P.; Wagner, R.; Khairuzzaman, W.; Ismail, W. Entrepreneurial ecosystems: A systematic review. J. Enterp. Commun. 2018, 12, 545-564. [CrossRef]

32. Lackéus, M.; Williams, K. Venture creation programs: Bridging entrepreneurship education and technology transfer. Educ. Train. 2015, 57, 48-73. [CrossRef]

33. Echeverri-Carroll, E. The IC2 Institute: A Think and Do Tank. Available online: http://lanic.utexas.edu/ project/etext/liilas/portal/portal099/think_tank.pdf (accessed on 18 June 2019).

34. Echeverri-Carroll, E. The growth of knowledge-based small firms in Monterrey, Mexico. Tex. Bus. Rev. 2008, 1-6. Available online: https://hdl.handle.net/2152/14465 (accessed on 18 July 2019).

35. PECTI 2016-2021 Plan Estatal de Desarrollo, Programa Especial Ciencia Tecnología e Innovación. Instituto de Innovación y Transferencia de Tecnología de Nuevo León. Available online: http://i2t2.org.mx/pdf/2017/ Programa\%20Especial\%20CTI\%202016\%20-\%202021.pdf (accessed on 18 June 2019).

36. CGIE. Maestría en Ciencias de la Comercialización de la Ciencia y Tecnología. Panorama General. Available online: http://cgie.org.mx/index.php/principal/panorama_general (accessed on 18 June 2019).

37. CGIE. Programa de Estudios. Available online: http://cgie.org.mx/index.php/principal/programa_estudio (accessed on 18 June 2019).

38. CGIE. Clean Tech Challenge Mexico. Available online: http://cgie.org.mx/index.php/principal/cleantech (accessed on 4 September 2019).

39. Nobi Norte Proyectos Seleccionados. Available online: http://www.nobi-norte.org/ (accessed on 4 September 2019).

40. Yeii Programa de Emprendimiento. Available online: http://yeii.org/ (accessed on 4 September 2019).

41. Tomato Valley Emprendimiento e Innovación Colectiva en Sinaloa. Available online: http://tomatovalley.net/ (accessed on 4 September 2019). 
42. CGIE. Changing Mexico. Available online: http://cgie.org.mx/index.php/main/changing_mexico (accessed on 4 September 2019).

43. Gora, A.A.; Ștefan, S.C.; Popa, S.C.; Albu, C.F. Students' Perspective on quality assurance in higher education in the context of sustainability: A PLS-SEM approach. Sustainability 2019, 11, 4793. [CrossRef]

44. Yin, R. Case Study Research; Sage: Thousand Oaks, CA, USA, 2009.

45. Stake, R. Investigación Como Estudio de Casos; Morata: Madrid, Spain, 2007.

46. Creswell, J.W.; Poth, C.N. Qualitative Inquiry and Research Design. Choosing Among Five Approaches; Sage Publications: California, USA, 2018.

47. Kozmetsky, G. Synergy for the 21st Century: Between unstructured problems and management planning controls. In Proceedings of the Conference for Operations Research and Management Sciences, Dallas, TX, USA, 27 October 1997.

(C) 2019 by the authors. Licensee MDPI, Basel, Switzerland. This article is an open access article distributed under the terms and conditions of the Creative Commons Attribution (CC BY) license (http://creativecommons.org/licenses/by/4.0/). 